\title{
Proposed System of Heart Attack Detection Using Internet of Things (IoT)
}

\author{
Ashima Gambhir \\ Assistant Professor \\ Amity University Gurgaon,Haryana,India \\ ashima.ashugambhir@gmail.com
}

\begin{abstract}
The concept of Internet of things has evolved over time. Using the Internet of things technology for heart attack detection by heartbeat sensing. We all know that you can take your life in Heart Attack 3 attempts but now in the first attempt it can be dangerous as well. If we regularly check our health every day, then we find out many different diseases in our body. Many of us lose ourselves due to irregularity of body checkups.. A life of heart attack the reason for this is their age, reduce Physical movement, age and many other factors. Heart attack detection is not easy to know and help our society. Diseases and attacks, In this paper, we are budding a scheme that reduce mortality and help in before time detection of heart invasion In this system we are implementing the heartbeat. Using surveillance and heart attack detection system Internet of things the sensor is then interfaced to one microcontroller that allows pulse rate readings to verify and broadcast them on the server. Users can set as high the heart rate beats at lower levels. After determining these limitations, the system starts monitoring and also intimates for less heart beating. For this, the system basically uses two circuits. One is transmission circuits that are with the patient and the other receiver circuit which is with the doctor or nurse for supervision. System uses Heart Beat Sensor to identify the recent pulse rate and show it on the Liquid Crystal Display(LCD) screen.
\end{abstract}

Keywords- Internet of Things(IOT), Heart beat sensing, Heart Attack Detection, ECG, Heart Beat Sensor.

With the help of Heart beat sensor, the system can detect temperature and pulse regularly. Doctor can set the verge

\section{INTRODUCTION}

Internet of Things(Style Internet of Things or IoT) Physical appliances, internetworking of vehicles (also Known as "Connected Device" and "Smart Devices"), embedded with buildings and other objects Electronics, software, sensors, actuators and networks connectivity that enables these objects to be assembled and exchange data Global Standards Initiative on 2013. Internet of Things (IoT-GSI) defined IoT as "the" Infrastructure of the information society "IoT allows the objects are controlled sensibly and / or remotely creating Opportunities for Existing Network Infrastructure. The more direct integration of the physical world into computer bed systems, and as a result of better efficiency, Accuracy and economic benefits.

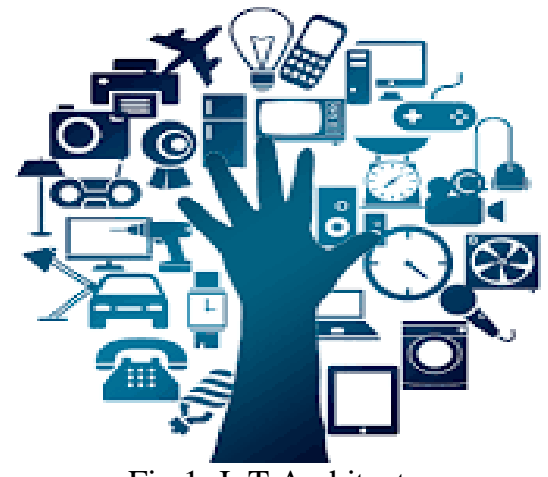

Fig 1: IoT Architecture value for all parameters. If these values cross the threshold limit, then system will send warning on internet or server using WIFI. With the help of Internet of Things(IoT), we interface anything, contact from anywhere and whenever, productively get to any administration and data about any article. By using an inserted sensor for heart beat detection which is continuously checks and assembly information.

The Internet of Things technology can offer large amount of data about time, space, person and object. IoT technology is also providing more potential of data processing, data collecting and some other new services.

\section{PROPOSED SYSTEM}

Figure 2 explains the system architecture of the proposed system.

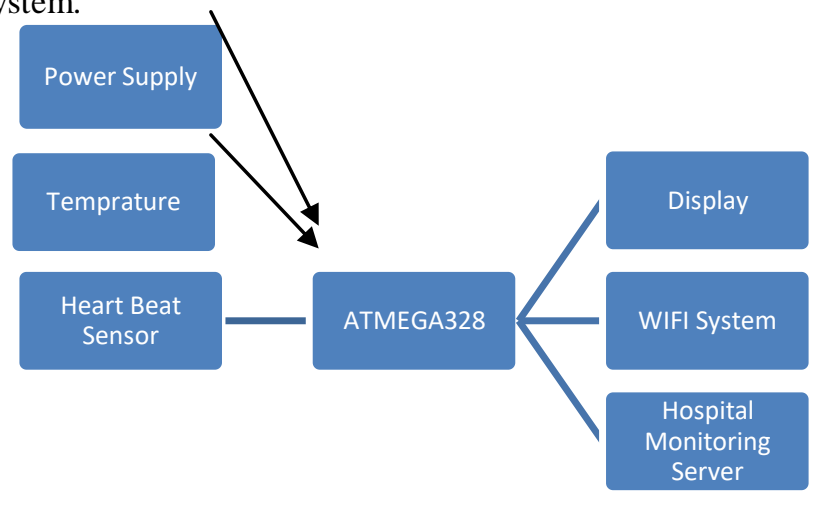

Fig 2 : Proposed System Architecture 


\section{Available online at www.ijrat.org}

Figure 3 explains the flow chart of proposed system.

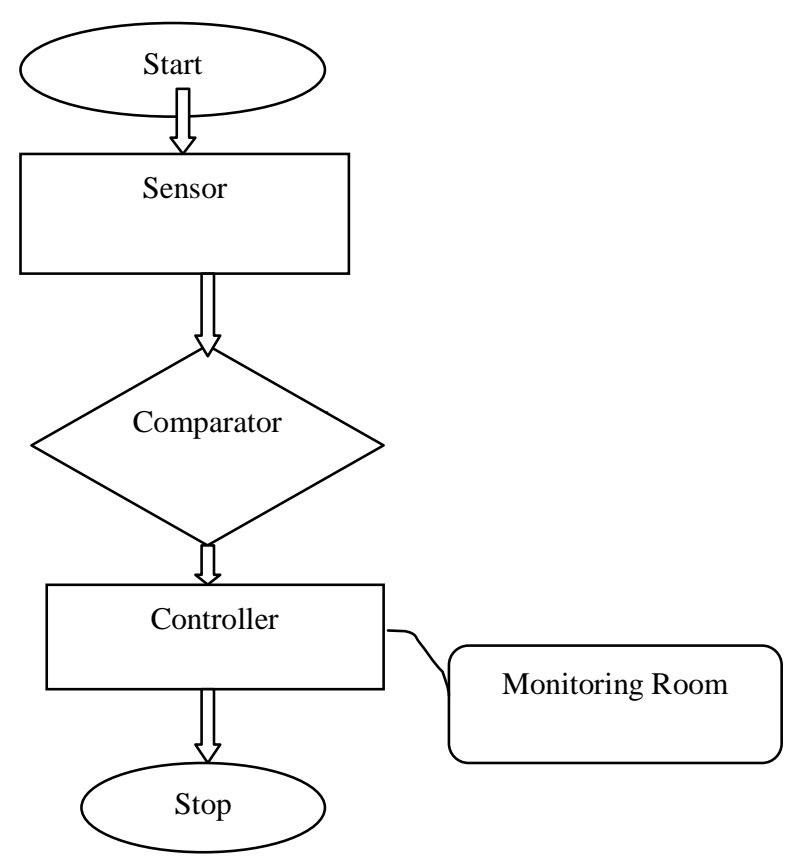

Fig 3: Flowchart of Proposed System

\section{COMPONENTS REQUIRED}

1. Temperature Sensor: LM35 sensor is the temperature sensor that is fundamentally used to gauge the temperature of human body .LM35 arrangement gadgets are IC(integrated circuit) temperature sensors, with a generation voltage is straightforwardly corresponding to temperature.

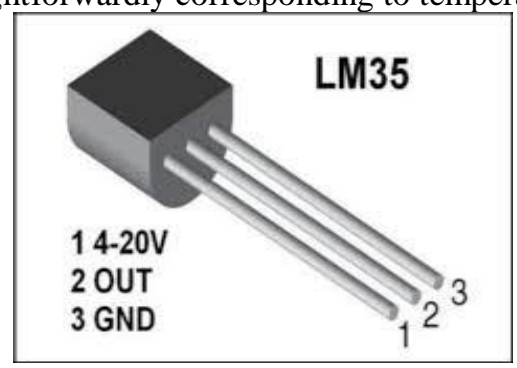

Fig 4: Temperature Sensor

\section{Pressure Sensor:}

The pressure sensor is basically used to compute the diastolic and systolic level of pressure in human body. It is deliberate in $\mathrm{mmHg}$.

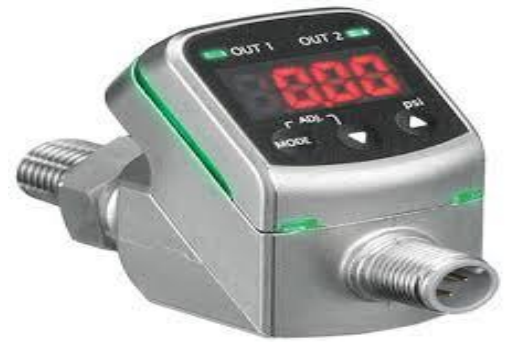

Fig 5: Pressure Sensor

3. Heart Beat Sensor:

Heart beat sensor is basically used to compute the heart rate that is in in digital output form.

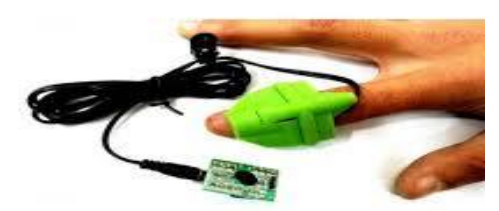

Fig 6: Heart Beat Sensor

\section{WiFi Module:}

The ESP8266 WiFi Module is an independent SOC with incorporated TCP/IP convention stack that can give any microcontroller access to your

$$
\text { WiFiarrange. }
$$

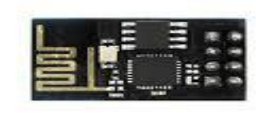

5. Atmega 328:

Fig 7: WiFi Module

Atmega 328 is 8 bit microcontroller. It is an Advanced Virtual RISC(AVR) based microcontroller. Its inbuilt internal memory is about 32KB.Figure 8 shows description of all pins of Atmega328.

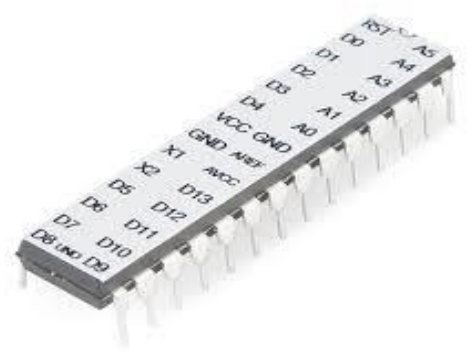

Fig 8: Atmega328 


\section{Available online at www.ijrat.org}

\section{METHODOLOGY}

This system basically uses two circuits:

1. Transmitting Circuit.

2. Receiver Circuit.

In this section, I explained the working methodology of heart attack detection using IoT. The framework detects the pulse rate sensor to determine the existing level of heart beat and display it on the LCD screen. The transmitting circuit joins AVR family microcontroller interfaced to LCD screen and this transmitting circuit is constrained by $12 \mathrm{~V}$ transformer. Also, the accepting circuit incorporates and RF beneficiary and likewise has a $12 \mathrm{~V}$ transformer. The range of temperature sensor is simple amount $0-135$ degree. Information of every body can recognized by sensor furthermore, diplay result is on LCD of $16^{*} 2$. All the while we these information tranfer to server and display in control room. We make this framework general for all the clinic rooms. Administrator can locate in single spot and ready to monitor all the patients at the same time.

\section{ADVANTAGES}

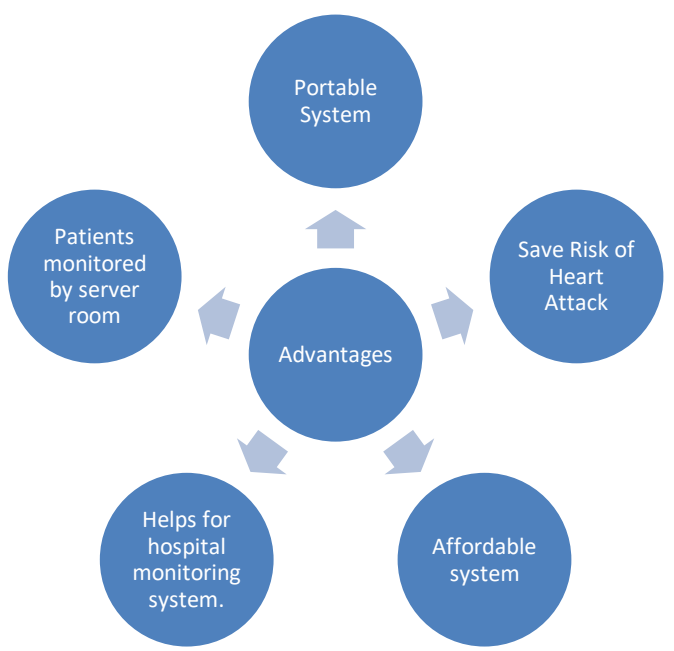

Fig 9: Advantages of Heart Attack Detection

\section{CONCLUSION}

Presently days we have an expanded danger of heart assaults. This framework which is essentially used to identify heart or heartbeat rate of human by utilizing heart beat sensors regardless of whether individual is at home. This framework additionally utilized for patients that are conceded in the medical clinic, all patient checked by single head in server room. This framework which estimates beat rate, body temperature and heartbeat of patient. we will cause this framework for creatures so we to can spare them. By our venture, If this proposed framework will grew then we can likewise identifies the heart blockage through this innovation.

\section{REFERENCES}

[1] Internet of things: internet of things, https://en.wikipedia.org/wiki/internet_of things.

[2] Effective Ways to Use Internet of Things in the field of Medical and Smart Health Care: Kaleem ullah, Munam ali Shah, Sijing zhang, IEEE Journal 2016.

[3] Heartbeat Monitoring and heart attack detection, Mamidi manisha , Katakan neeraja, International Journal of Innovations in Engineering and Technology(IJIET).

[4]Heartbeat Sensing and Heart Attack Detection using Internet of Things, International Journal of Engineering Science and Computing(IJESC).

[5]Heart Rate monitoring And Heart Attack Detection Using Wearable Device, International Journal of Technical Research and Application(IJTRA).

[6] Mobile based Horne Automation using Internet of Things(IOT),Kumar Mandula, Ram Parupalli, E.Magesh,2015 International Conference on Control, Instrumentation, Communication and Computational Technologies(ICCICCT).

[7] http://www.thehealthsite.com/diseasesconditions/heartdisease-in-india-6-shocking-shouldknown/

[8]http://ieeexplore.ieee.org/xpl/articleDetails.jsp?arnumb er $=4561963 \&$ queryText $=$ heart $\% 20$ attack $\% 20$ sensor\&new $\mathrm{s}$ earch $=$ true 